\title{
Lipid and fatty acid composition of freshwater cyanobacteria
}

\author{
A. K. Sallal, N. A. Nimer and S. S. Radwan* \\ Department of Botany and Microbiology, Faculty of Science, Kuwait University, PO Box 5969, Safat 13060, Kuwait
}

(Received 20 March 1990; revised 1 June 1990; accepted 18 June 1990)

\begin{abstract}
Four species of freshwater cyanobacteria (Anabaena cylindrica, Anacystis nidulans, Nostoc canina and Nostoc muscorum) contained as major lipid classes monogalactosyldiacylglycerols, digalactosyldiacylglycerols, sulphoquinovosyldiacylglycerols and phosphatidylglycerols. Unlike photosynthetic eukaryotes, cyanobacteria incubated for $\mathbf{7} \mathrm{d}$ in the dark suffered no decrease in the concentrations of these classes, except for $\mathbf{N}$. muscorum. Growth, photosynthesis and nitrogen fixation were $30-40 \%$ lower after dark incubation. The nitrogen-fixing cyanobacteria, Anabaena cylindrica, $N$. canina and $N$. muscorum, contained alcohol glycosides and a highly-polar unknown glycolipid at high concentrations. The proportion of these two lipid classes decreased in the dark in $N$. muscorum alone. Extracts from Anacystis nidulans and $N$. canina, and to a lesser extent $N$. muscorum, contained sterols, whose concentration increased after dark incubation. Anabaena cylindrica contained considerable concentrations of linolenic acid in its total lipid, which did not decrease on dark incubation, and was not present mainly in monogalactosyldiacylglycerols as in photosynthetic eukaryotes. Palmitoleic acid, which is primarily confined to phosphatidylglycerols in photosynthetic eukaryotes, was distributed among the major lipid classes of N. canina.
\end{abstract}

\section{Introduction}

Although the major lipid classes in cyanobacteria and photosynthetic eukaryotes are quite similar (Quinn \& Williams, 1983) the fatty acid compositions of their lipids are not. Lipids from photosynthetic eukaryotes are rich in polyenoic fatty acids (for reviews see Kates, 1970; Radwan \& Mangold, 1976, 1980), but with a few exceptions (Nichols \& Wood, 1968a; Sato \& Morata, $1980,1982)$, they are absent from cyanobacterial lipids (Holton et al., 1964; Parker et al., 1967). Moreover, cyanobacteria, in contrast to eukaryotes, usually lack sterols (Quinn \& Williams, 1983).

Dark incubation of photosynthetic eukaryotes is usually associated with decreases in the concentration of the major lipid classes, and of the constituent linolenic acid (Kates, 1970; Radwan et al., 1979). An earlier study in our laboratory indicated that different marine cyanobacteria do not exhibit similar changes in their lipids in response to dark incubation (Al-Hasan et al., 1989). The present paper contains data on the lipid and fatty acid composition of four freshwater cyanobacteria, three of which differ from the marine cyanobacteria we studied earlier, in that they can fix nitrogen. Preliminary analyses indicate considerable differences in lipid composition between these freshwater cyanobacteria and the marine species studied earlier.

\section{Methods}

Organisms and growth conditions. Anabaena cylindrica (CU 1403/2a) and Nostoc muscorum (1453/9) were obtained from the Culture Centre of Algae and Protozoa, Cambridge, UK. Anacystis nidulans and Nostoc canina were a gift from Professor G. A. Codd, University of Dundee, UK. The cyanobacteria were grown axenically at $28^{\circ} \mathrm{C}$ in the basic BG-11 medium (Stainer et al., 1971) in aspirators (10 litre) equipped with magnetic stirrers and sparged with sterile air. Light of $3500 \mathrm{~lx}$ at the surfaces of the vessels was provided by cool-white fluorescent tubes. The ferricyanide Hill reaction (PS II), Mehler reaction (PS I), NADPphotoreduction and oxygen evolution were measured as described by Sallal \& Nimer $(1988 a, b)$. Nitrogen-fixing cyanobacteria were grown in nitrogen-free medium, and nitrogenase was assayed by the method of Haystead et al. (1970) using a Porapak-T column. For lipid analysis, cultures were either grown under white light for $7 \mathrm{~d}$ and then incubated for another $7 \mathrm{~d}$ in the dark, or else maintained under continuous illumination throughout the $14 \mathrm{~d}$ period. At the end of the culture period, the biomass was allowed to settle and the supernatant was decanted, reducing the 101 volume to about $500 \mathrm{ml}$. The biomass was then harvested by centrifugation and the pellet was suspended in about 20 vols of 2-propanol/chloroform $(1: 2, v / v)$, ready for lipid analysis.

Lipid extractions and analysis. All solvents were freshly redistilled, and all steps were done under oxygen-free nitrogen, as far as feasible. The total lipid was extracted from cyanobacteria with 2-propanol/ chloroform $(1: 2, \mathrm{v} / \mathrm{v})$ (Nichols, 1964), and purified according to Folch et al. (1957). Boiling solvents were used in the first extraction to deactivate lipases (Kates, 1972; Radwan, 1984). The lipid extracts were analysed by thin-layer chromatography (TLC) on plates of silica gel. Nonpolar lipid classes were fractionated using hexane/diethyl ether/ acetic acid (90:10:1, by vol.) (Mangold \& Malins, 1960). To improve the resolution of sterols, we used hexane/diethyl ether/acetic acid 
( $50: 50: 1$, by vol.). Ionic and other polar lipids were resolved by twodimensional TLC using chloroform/methanol/7 M-ammonium hydroxide ( $65: 25: 4$, by vol.) in the first direction and chloroform/methanol/ acetic acid/water (170:25:25:4, by vol.) in the second (Nichols, 1964). The lipid fractions were detected with iodine vapour or by charring after spraying the chromatograms with $50 \%(\mathrm{v} / \mathrm{v}) \mathrm{H}_{2} \mathrm{SO}_{4}$. Individual lipid classes were identified by their chromotographic behaviour using standards and specific spray reagents (Dittmer \& Lester, 1964; Siakotos \& Rouser, 1965; Stahl, 1967, Vioque, 1984). Sterols were identified by the characteristic deep pink colour with $50 \%$ methanolic $\mathrm{H}_{2} \mathrm{SO}_{4}$ at $100{ }^{\circ} \mathrm{C}$ and characteristic fluorescence under $\mathrm{UV}$ with antimony trichloride/acetic acid, chlorosulphonic acid/acetic acid, perchloric acid, bismuth trichloride and methanolic $\mathrm{ZnCl}_{2}$ (Stahl, 1967). Sterol fractions were eluted from thin-layer chromatograms with chloroform/diethyl ether/ethanol (1:1:1, by vol.) (Kates, 1972) and analysed by UV-spectrophotometry (Pye-Unicam SP 800) and gas chromatography (Pye-Unicam 204) as their trimethylsilyl ether derivates using a column packed with OV-17 on Chromosorb W-HP. To confirm the identity of a glycolipid tentatively identified as alcohol glycoside, and that of a very polar unknown glycolipid, samples of the pure compounds were separated by preparative TLC, eluted (Kates, 1972), and subjected to acid hydrolysis (Gaver \& Sweeley, 1965). Hydrolysis products soluble in hexane were analysed by TLC, and sugar moieties remaining in the aqueous phases were identified by paper chromatography (Menzies \& Seakins, 1976). Samples of total lipids and individual lipid classes, separated by preparative TLC (Radwan, 1978), were subjected to methanolysis with $2 \% \mathrm{H}_{2} \mathrm{SO}_{4}$ in absolute methanol at $90^{\circ} \mathrm{C}$ for $90 \mathrm{~min}$ (Chalvardjian, 1964). The resulting methyl esters of fatty acids were recovered with hexane, purified by preparative TLC and analysed by gas chromatography using a glass column $(1.83 \mathrm{~m} \times 4 \mathrm{~mm}$ i.d.) packed with $15 \%(\mathrm{w} / \mathrm{w})$ DEGS on Anakrom D (100:120 mesh) and operated isothermally at $170^{\circ} \mathrm{C}$ with nitrogen as the carrier gas. Individual fatty acids were identified by comparing their retention times with those of standard samples, and by the 'equivalent chain length' method of Miwa et al. (1960).

\section{Results}

\section{Growth and physiological activity}

$N$. canina and $N$. muscorum grew for about 2 doublings under continuous illumination during the first $12 \mathrm{~d}$, after which their growth slowed. Incubating $7 \mathrm{~d}$ light-grown cultures in the dark for another $7 \mathrm{~d}$ did not increase the biomass. The dark-incubated cells resumed slow growth after reillumination. When $7 \mathrm{~d}$ light-grown cultures of $N$. canina and $N$. muscorum were incubated for $7 \mathrm{~d}$ in the dark, there was a $30-40 \%$ decrease in their lightdependent photosynthetic and nitrogen fixation activities (data not shown).

\section{Lipid composition}

The total lipid content of the four cyanobacterial species ranged between 10.7 and $12.3 \%$ of dry weight. There was no obvious difference in the lipid content between lightand dark-incubated cultures. Thin-layer chromatograms indicated the presence of hydrocarbons, diacylglycerols,

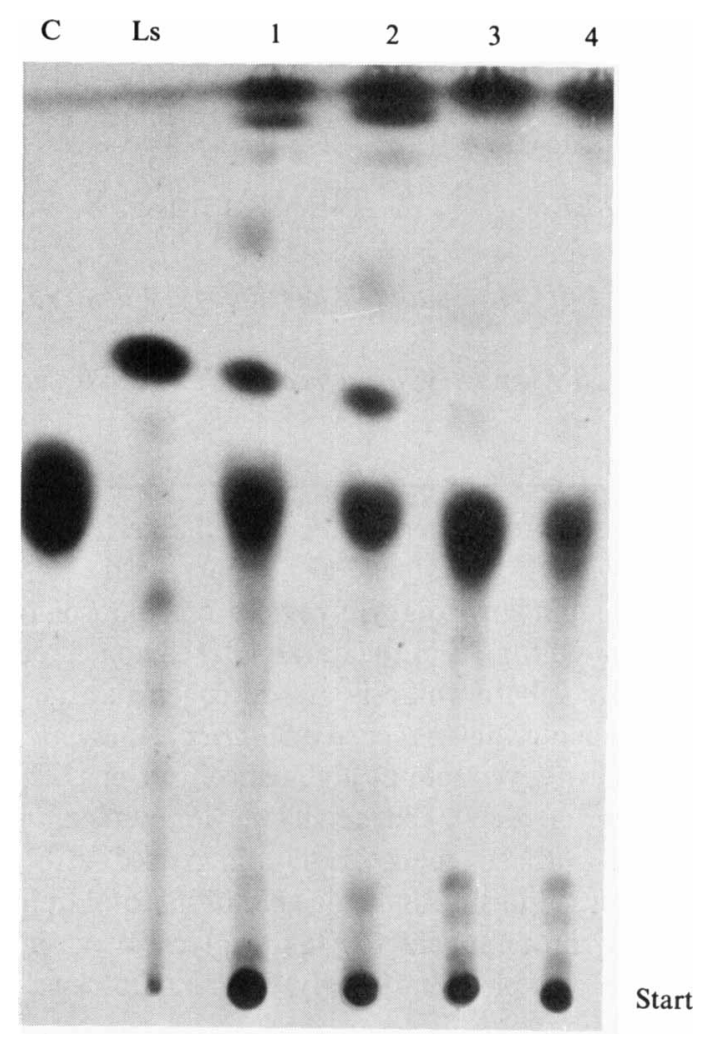

Fig. 1. Typical TLC plate showing individual sterols in the lipids of light- and dark-incubated cells of Anacystis nidulans and Nostoc canina. TLC was done using silica gel G plates and hexane/diethyl ether/acetic acid (50:50:1, by vol.). Sterols were visualized by charring after spraying with $50 \% \mathrm{H}_{2} \mathrm{SO}_{4}$. Lanes 1 and $2, N$. canina in the light (lane 1 ) and in the dark (lane 2); lanes 3 and 4, Anacystis nidulans in the light (lane 3) and in the dark (lane 4). Ls, lanosterol; C, cholesterol.

monoacylglycerols and pigments in the nonpolar lipid fraction. All extracts, except those from Anacystis nidulans, also contained free fatty acids. Lipids from Anacystis nidulans contained appreciable concentrations of cholesterol, and those from $N$. canina considerable amounts of cholesterol and lanosterol (Fig. 1).

The predominant polar lipid classes in all extracts were monogalactosyldiacylglycerols, digalactosyldiacylglycerols, sulphoquinovosyldiacylglycerols and phosphatidylglycerols (Fig. 2). In addition, all extracts except those from Anacystis nidulans contained high concentrations of alcohol glycosides and a highly-polar unknown glycolipid. The identity of the alcohol glycoside fraction, isolated from a light-incubated culture of Anabaena cylindrica by preparative TLC, was confirmed by identifying its acid-hydrolysis products. The aqueous phase contained glucose and the hexane phase contained long-chain alcohols, identified by their TLC behaviour and IR absorption band at $3500 \mathrm{~cm}^{-1}$. The unknown glycolipid gave a positive reaction with $\alpha$-naphthol 


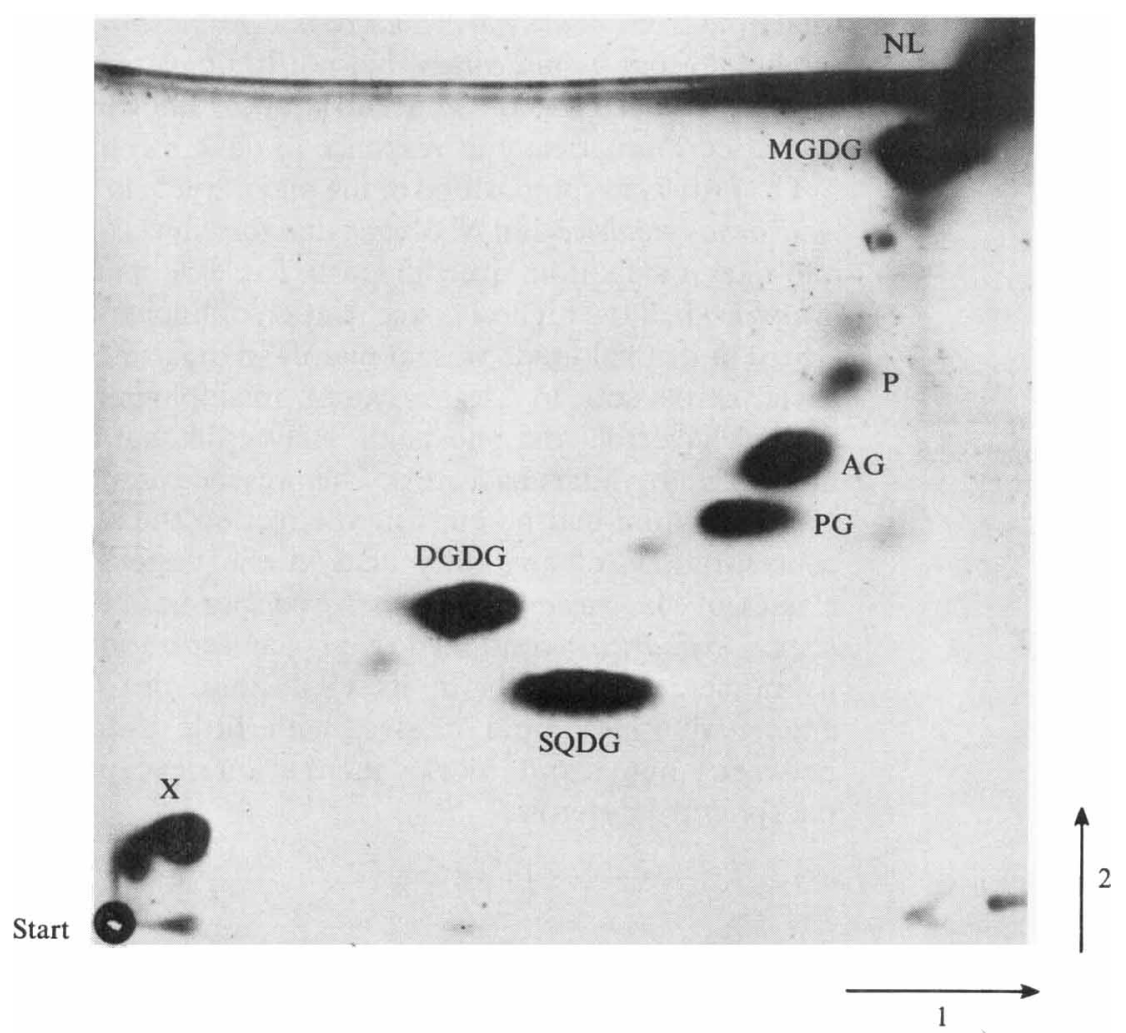

Fig. 2. Typical two-dimensional thin-layer chromatogram showing the composition of lipid classes of $N$. canina. TLC was done using silica gel G plates and the following solvent systems: chloroform/methanol/ $7 \mathrm{M}$-ammonium hydroxide $(65: 25: 4$, by vol.) in the first direction, and chloroform/methanol/acetic acid/ water $(170: 25: 25: 2$, by vol.) in the second direction. The lipid fractions were visualized by charring after spraying with $50 \% \mathrm{H}_{2} \mathrm{SO}_{4}$. NL, neutral lipids and pigments; MGDG, monogalactosyldiacylglycerols; P, pigments; AG, alcohol glycosides: PG, phosphatidylglycerols; DGDG, digalactosyldiacylglycerols; SQDG, sulphoquinovosyldiacylglycerols; $X$, unknown glycolipid. (i.e. sugar positive), a weak reaction with ninhydrin, and contained no phosphorus. Acid hydrolysis of this fraction, isolated from a light-incubated culture of $N$. muscorum, showed that it was an acylglycolipid (the fatty acid composition is given in Table 2) containing approximately equal proportions of glucose and galactose (as indicated by their spot densities on paper chromatograms). Several other unidentified polar lipids occurred in various extracts in trace amounts.

The composition of major glycolipids in extracts from light-incubated cyanobacteria was similar to that from dark-incubated cultures (Fig. 3). The only exception was $N$. muscorum, in which dark-incubated cultures contained lower concentrations of the major glycolipids than did light-incubated cultures.

\section{Fatty acid compositions}

The fatty acid compositions of lipids from the test cyanobacteria are shown in Tables 1 and 2 . The predominant fatty acids in lipids from Anacystis nidulans (Table 1) were palmitic (16:0) and palmitoleic (16:1) acids. In lipids of Anabaena cylindrica (Table 1) palmitic, linoleic (18:2) and linolenic (18:3) acids predominated. $N$. canina lipids contained palmitic, palmitoleic, oleic $(18: 1)$ and linoleic acids as major acyl moieties, whereas
Table 1. Fatty acid composition of total lipid from nonnitrogen-fixing (Anacystis nidulans) and nitrogen-fixing

(Anabaena cylindrica) cyanobacteria

Light cultures were maintained for $14 \mathrm{~d}$ under continuous illumination. Dark cultures were grown for the first $7 \mathrm{~d}$ in the light and were then maintained for another $7 \mathrm{~d}$ in the dark. Values are expressed as $w t \%$; each value is the mean of three determinations, \pm SD. tr, trace.

\begin{tabular}{lccccc}
\hline & \multicolumn{2}{c}{ Anacystis nidulans } & & \multicolumn{2}{c}{ Anabaena cylindrica } \\
\cline { 2 - 3 } \cline { 5 - 6 } $\begin{array}{l}\text { Fatty } \\
\text { acid }\end{array}$ & Light & Dark & & Light & Dark \\
\hline $16: 0$ & $41.8 \pm 2.0$ & $56.2 \pm 2.0$ & & $47.6 \pm 1.9$ & $44.9 \pm 2.1$ \\
$16: 1$ & $30.1 \pm 0.6$ & $31.7 \pm 1.5$ & & $1.7 \pm 0.1$ & $2.0 \pm 0.1$ \\
$16: 2$ & $7.6 \pm 0.3$ & tr & & $10.1 \pm 0.6$ & $11.5 \pm 0.9$ \\
$18: 0$ & $6.4 \pm 0.2$ & $5.8 \pm 0.2$ & & tr & tr \\
$18: 1$ & $11.2 \pm 0.6$ & $5 \cdot 8 \pm 0.3$ & & $8.4 \pm 0.5$ & $12.6 \pm 0.7$ \\
$18: 2$ & $2.3 \pm 0.1$ & $0.5 \pm 0.0$ & & $17.5 \pm 1.2$ & $15.4 \pm 0.8$ \\
$18: 3$ & tr & tr & & $13.7 \pm 0.5$ & $13.5 \pm 0.7$ \\
\hline \hline
\end{tabular}

in $N$. muscorum palmitic, palmitoleic, hexadecadienoic (16:2), oleic and linoleic acids were predominant (Table 2). In the total lipid from Anacystis nidulans and $N$. canina, the dark incubation was associated with increased concentration of palmitic acid and decreased concentration of oleic acid. The converse was true for the 


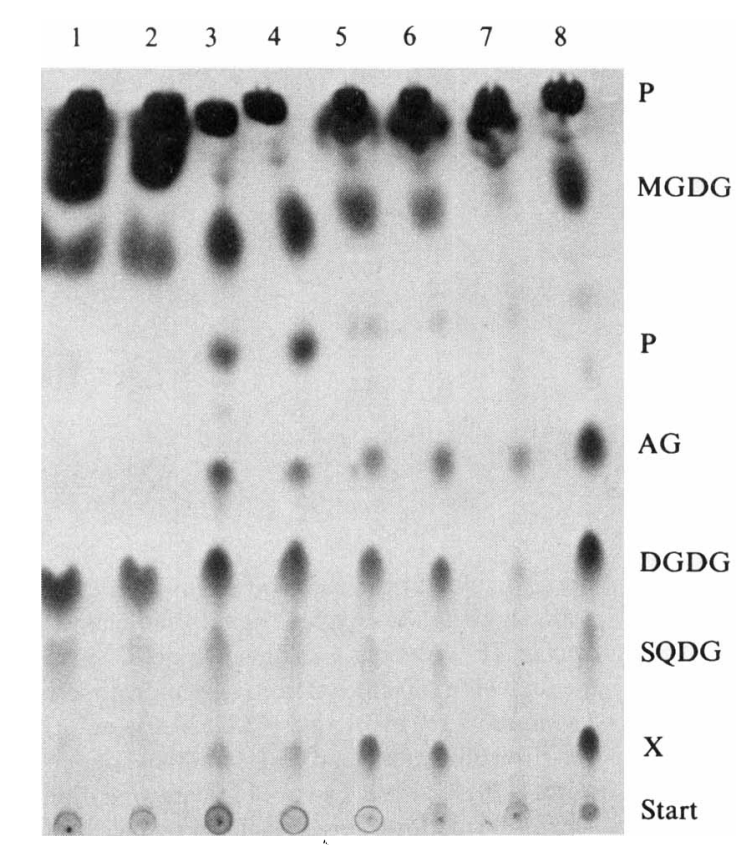

Fig. 3. Typical TLC plate showing the effect of illumination on glycolipids of the four cyanobacteria. TLC was done using silica gel G and chloroform/methanol/acetic acid/water (85:12:12:1, by vol.). The glycolipid fractions were visualized by spraying with $\alpha$-naphthol and $\mathrm{H}_{2} \mathrm{SO}_{4}$ and heating at $100^{\circ} \mathrm{C}$. MGDG, monogalactosyldiacylglycerols; $P$, pigments; AG, alcohol glycosides; DGDG, digalactosyldiacylglycerides; SQDG, sulphoquinovosyldiacylglycerols; $X$, unknown glycolipid. Lanes 1 and 2, Anacystis nidulans in the dark (lane 1) and in the light (lane 2); lanes 3 and 4, Anabaena cylindrica in the dark (lane 3) and in the light (lane 4); lanes 5 and 6, N. canina in the dark (lane 5) and in the light (lane 6); lanes 7 and 8, $N$. muscorum in the dark (lane 7) and in the light (lane 8). total lipid from Anabaena cylindrica and N. muscorum. In the lipids from $N$. muscorum, but not in lipids from the other cyanobacteria, the concentration of linoleic acid decreased dramatically in response to dark incubation.

The fatty acid composition of the major lipid classes of Anabaena cylindrica and N. canina, and the effects of light and dark incubation, are shown in Table 3. Anabaena cylindrica had the highest concentration of linolenic acid $(18: 3)$ in its total lipid, present mainly in digalactosyldiacylglycerols and, to a lesser extent, in sulphoquinovosyldiacylglycerols and phosphatidylglycerols, but not in monogalactosyldiacylglycerols. The presence or absence of illumination had no consistent effect on the relative concentrations of any fatty acid in the various lipid classes of Anabaena cylindrica. N. canina, unlike Anabaena cylindrica, contained high concentrations of palmitoleic acid $(16: 1)$ in its total lipid, distributed among all major lipid classes, with little difference between light and dark incubation except for phosphatidylglycerols.

\section{Discussion}

Our results show that freshwater cyanobacteria do not respond uniformly to the presence or absence of illumination with respect to changes in their lipid composition. This constitutes additional evidence for the heterogeneity of these photosynthetic prokaryotes as a systematic group and echoes our earlier results on marine

Table 2. Effect of dark-incubation on the constituent fatty acids of total lipid from two Nostoc spp. at different growth stages

Values are expressed as $w t \%$, each value is the mean of three determinations, $\pm \mathrm{SD}$. $\mathrm{tr}$, trace.

\begin{tabular}{|c|c|c|c|c|c|c|c|c|c|c|c|c|c|c|}
\hline \multirow{3}{*}{$\begin{array}{l}\text { Fatty } \\
\text { acid }\end{array}$} & \multicolumn{7}{|c|}{ Nostoc canina } & \multicolumn{7}{|c|}{ Nostoc muscorum } \\
\hline & \multirow{2}{*}{$\frac{7 \mathrm{~d}}{\text { Light }}$} & \multicolumn{2}{|c|}{$9 d$} & \multicolumn{2}{|c|}{$12 \mathrm{~d}$} & \multicolumn{2}{|c|}{$14 \mathrm{~d}$} & \multirow{2}{*}{$\frac{7 \mathrm{~d}}{\text { Light }}$} & \multicolumn{2}{|c|}{$9 \mathrm{~d}$} & \multicolumn{2}{|c|}{$12 \mathrm{~d}$} & \multicolumn{2}{|c|}{$14 \mathrm{~d}$} \\
\hline & & Light & Dark & Light & Dark & Light & Dark & & Light & Dark & Light & Dark & Light & Dark \\
\hline $16: 0$ & $\begin{array}{r}23.0 \\
\pm 1.0\end{array}$ & $\begin{array}{r}23 \cdot 1 \\
\pm 1 \cdot 0\end{array}$ & $\begin{array}{r}30.3 \\
\pm 1.1\end{array}$ & $\begin{array}{r}27.0 \\
\pm 1.5\end{array}$ & $\begin{array}{r}38.8 \\
\pm 2.0\end{array}$ & $\begin{array}{r}26.9 \\
\pm 1.7\end{array}$ & $\begin{array}{r}39.1 \\
\pm 1.6\end{array}$ & $\begin{array}{r}21.9 \\
\pm 1.5\end{array}$ & $\begin{array}{r}21.9 \\
\pm 1.3\end{array}$ & $\begin{array}{r}22.0 \\
\pm 0.6\end{array}$ & $\begin{array}{r}22.0 \\
\pm 1.3\end{array}$ & $\begin{array}{r}17.5 \\
\pm 1.0\end{array}$ & $\begin{array}{r}21.6 \\
\pm 0.8\end{array}$ & $\begin{array}{r}17.0 \\
\pm 0.8\end{array}$ \\
\hline $16: 1$ & $\begin{array}{r}24.0 \\
\pm 1.4\end{array}$ & $\begin{array}{r}24.0 \\
\pm 0.7\end{array}$ & $\begin{array}{r}22.4 \\
\pm 1.2\end{array}$ & $\begin{array}{r}22.9 \\
\pm 0.9\end{array}$ & $\begin{array}{r}20.0 \\
\pm 1.0\end{array}$ & $\begin{array}{r}23.2 \\
\pm 0.9\end{array}$ & $\begin{array}{r}20.2 \\
\pm 1.2\end{array}$ & $\begin{array}{r}19.5 \\
\pm 1.1\end{array}$ & $\begin{array}{r}19.7 \\
\pm 0.7\end{array}$ & $\begin{array}{r}20.0 \\
\pm 1.3\end{array}$ & $\begin{array}{r}19 \cdot 3 \\
\pm 0.6\end{array}$ & $\begin{array}{r}20.2 \\
\pm 1.2\end{array}$ & $\begin{array}{r}19.0 \\
\pm 1.1\end{array}$ & $\begin{array}{r}20.0 \\
\pm 0.9\end{array}$ \\
\hline $16: 2$ & $\begin{array}{r}2.8 \\
\pm 0.1\end{array}$ & $\begin{array}{r}3.0 \\
\pm 0.1\end{array}$ & $\begin{array}{r}3.5 \\
\pm 0.1\end{array}$ & $\begin{array}{r}3.7 \\
\pm 0.1\end{array}$ & $\begin{array}{r}4.0 \\
\pm 0.1\end{array}$ & $\begin{array}{r}3.9 \\
\pm 0.1\end{array}$ & $\begin{array}{r}4.2 \\
\pm 0.2\end{array}$ & $\begin{array}{r}15.9 \\
\pm 0.4\end{array}$ & $\begin{array}{r}16.0 \\
\pm 0.8\end{array}$ & $\begin{array}{r}17.0 \\
\pm 1.0\end{array}$ & $\begin{array}{r}16 \cdot 0 \\
\pm 0.9\end{array}$ & $\begin{array}{r}22 \cdot 0 \\
\pm 0.8\end{array}$ & $\begin{array}{r}16.0 \\
\pm 1.0\end{array}$ & $\begin{array}{r}21.6 \\
\pm 1.7\end{array}$ \\
\hline $18: 0$ & $\begin{array}{r}1.3 \\
\pm 0.0\end{array}$ & $\begin{array}{r}0.9 \\
\pm 0.0\end{array}$ & $\begin{array}{r}0.4 \\
\pm 0.0\end{array}$ & $\operatorname{tr}$ & $\operatorname{tr}$ & $\operatorname{tr}$ & tr & tr & tr & $\mathbf{t r}$ & tr & $\operatorname{tr}$ & $\begin{array}{r}1.6 \\
\pm 0.1\end{array}$ & tr \\
\hline $18: 1$ & $\begin{array}{r}30 \cdot 2 \\
\pm 1.2\end{array}$ & $\begin{array}{r}29.8 \\
\pm 1 \cdot 1\end{array}$ & $\begin{array}{r}15.8 \\
\pm 0.9\end{array}$ & $\begin{array}{r}29.0 \\
\pm 1.3\end{array}$ & $\begin{array}{r}11.0 \\
\pm 0.7\end{array}$ & $\begin{array}{r}29.2 \\
\pm 1.8\end{array}$ & $\begin{array}{r}10.9 \\
\pm 0.5\end{array}$ & $\begin{array}{r}14.7 \\
\pm 0.8\end{array}$ & $\begin{array}{r}14.5 \\
\pm 0.4\end{array}$ & $\begin{array}{r}19.2 \\
\pm 0.5\end{array}$ & $\begin{array}{r}15.3 \\
\pm 0.6\end{array}$ & $\begin{array}{r}28.9 \\
\pm 1.4\end{array}$ & $\begin{array}{r}14.2 \\
\pm 0.4\end{array}$ & $\begin{array}{r}29.7 \\
\pm 1.7\end{array}$ \\
\hline $18: 2$ & $\begin{array}{r}18.0 \\
\pm 1.0\end{array}$ & $\begin{array}{r}17.8 \\
\pm 0.5\end{array}$ & $\begin{array}{r}26.8 \\
\pm 1.3\end{array}$ & $\begin{array}{r}16.0 \\
\pm 0.8\end{array}$ & $\begin{array}{r}26.0 \\
\pm 1.0\end{array}$ & $\begin{array}{r}16.0 \\
\pm 0.9\end{array}$ & $\begin{array}{r}25.6 \\
\pm 1.0\end{array}$ & $\begin{array}{r}26.4 \\
\pm 0.8\end{array}$ & $\begin{array}{r}26.7 \\
\pm 1.0\end{array}$ & $\begin{array}{r}21.5 \\
\pm 1.2\end{array}$ & $\begin{array}{r}26.8 \\
\pm 1.4\end{array}$ & $\begin{array}{r}11.4 \\
\pm 0.7\end{array}$ & $\begin{array}{r}27 \cdot 1 \\
\pm 0 \cdot 8\end{array}$ & $\begin{array}{r}11.7 \\
\pm 0.4\end{array}$ \\
\hline $18: 3$ & $\begin{array}{r}0.4 \\
\pm 0.0\end{array}$ & $\begin{array}{r}0.7 \\
\pm 0.0\end{array}$ & $\begin{array}{r}0.6 \\
\pm 0.1\end{array}$ & $\begin{array}{r}0.9 \\
\pm 0.0\end{array}$ & tr & $\begin{array}{r}0.9 \\
\pm 0.1 \\
\end{array}$ & $\operatorname{tr}$ & $\begin{array}{r}0.4 \\
\pm 0.1\end{array}$ & $\begin{array}{r}0.5 \\
\pm 0.1\end{array}$ & $\operatorname{tr}$ & $\begin{array}{r}0.4 \\
\pm 0.0\end{array}$ & tr & $\begin{array}{r}0.3 \\
\pm 0.0\end{array}$ & $\operatorname{tr}$ \\
\hline
\end{tabular}


Table 3. Constituent fatty acids of individual lipid classes from two cyanobacteria

Light cultures were maintained for $14 \mathrm{~d}$ under continuous illumination. Dark cultures were grown for the first $7 \mathrm{~d}$ in the light and were then maintained for another $7 \mathrm{~d}$ in the dark. Values are expressed as wt \%; each value is the mean of two determinations, \pm SD. $\operatorname{tr}$, trace.

\begin{tabular}{|c|c|c|c|c|}
\hline \multirow{2}{*}{$\begin{array}{l}\text { Fatty } \\
\text { acid }\end{array}$} & \multicolumn{2}{|c|}{ Anabaena cylindrica } & \multicolumn{2}{|c|}{ Nostoc canina } \\
\hline & Light & Dark & Light & Dark \\
\hline \multicolumn{5}{|c|}{ Monogalactosyldiacylglycerols: } \\
\hline $16: 0$ & $56 \cdot 0 \pm 1 \cdot 0$ & $24 \cdot 4 \pm 1 \cdot 1$ & $11.5 \pm 0.4$ & $12 \cdot 1 \pm 0 \cdot 5$ \\
\hline $16: 1$ & $1 \cdot 1 \pm 0 \cdot 0$ & tr & $21.6 \pm 0.9$ & $26 \cdot 1 \pm 1 \cdot 2$ \\
\hline $16: 2$ & $12 \cdot 1 \pm 0 \cdot 5$ & $24 \cdot 2 \pm 0 \cdot 9$ & $25 \cdot 6 \pm 1 \cdot 1$ & $24 \cdot 9 \pm 1 \cdot 2$ \\
\hline $18: 0$ & $12 \cdot 1 \pm 0.4$ & $\operatorname{tr}$ & $\operatorname{tr}$ & $\operatorname{tr}$ \\
\hline $18: 1$ & $25.2 \pm 0.8$ & $29 \cdot 1 \pm 1 \cdot 2$ & $21 \cdot 6 \pm 0.4$ & $24 \cdot 7 \pm 1 \cdot 3$ \\
\hline $18: 2$ & $1 \cdot 6 \pm 0 \cdot 1$ & $20 \cdot 5 \pm 1 \cdot 2$ & $19 \cdot 7 \pm 1 \cdot 0$ & $8 \cdot 7 \pm 0 \cdot 1$ \\
\hline $18: 3$ & $2 \cdot 8 \pm 0.1$ & $1.8 \pm 0.0$ & $\operatorname{tr}$ & $3 \cdot 4 \pm 0.1$ \\
\hline \multicolumn{5}{|c|}{ Digalactosyldiacylglycerols: } \\
\hline $16: 0$ & $20 \cdot 0 \pm 1 \cdot 0$ & $20 \cdot 7 \pm 1 \cdot 0$ & $1 \cdot 7 \pm 0 \cdot 1$ & $12.5 \pm 0.7$ \\
\hline $16: 1$ & $\overline{t r}$ & $\overline{t r}$ & $28 \cdot 7 \pm 1 \cdot 4$ & $23 \cdot 6 \pm 1 \cdot 1$ \\
\hline $16: 2$ & $26 \cdot 5 \pm 1 \cdot 1$ & $27 \cdot 6 \pm 1 \cdot 6$ & $28 \cdot 8 \pm 0.8$ & $24 \cdot 5 \pm 1 \cdot 2$ \\
\hline $18: 0$ & $0.3 \pm 0.0$ & $\operatorname{tr}$ & $\operatorname{tr}$ & $\operatorname{tr}$ \\
\hline $18: 1$ & $24 \cdot 3 \pm 1 \cdot 7$ & $28 \cdot 2 \pm 0 \cdot 8$ & $27 \cdot 0 \pm 1 \cdot 6$ & $30 \cdot 3 \pm 1 \cdot 8$ \\
\hline $18: 2$ & $12 \cdot 3 \pm 0 \cdot 6$ & $15 \cdot 1 \pm 0 \cdot 4$ & $5 \cdot 6 \pm 0 \cdot 1$ & $9 \cdot 0 \pm 0.2$ \\
\hline $18: 3$ & $16.5 \pm 0.5$ & $8 \cdot 3 \pm 0 \cdot 1$ & $\mathbf{t r}$ & $\operatorname{tr}$ \\
\hline \multicolumn{5}{|c|}{ Sulphoquinovosyldiacylglycerols: } \\
\hline $16: 0$ & $17 \cdot 8 \pm 0.8$ & $24 \cdot 6 \pm 0.7$ & $9 \cdot 1 \pm 0.5$ & $8.0 \pm 0.6$ \\
\hline $16: 1$ & $\operatorname{tr}$ & $\operatorname{tr}$ & $28.5 \pm 1.7$ & $29 \cdot 2 \pm 1 \cdot 2$ \\
\hline $16: 2$ & $35 \cdot 1 \pm 1 \cdot 1$ & $23 \cdot 1 \pm 1 \cdot 2$ & $30 \cdot 6 \pm 1 \cdot 2$ & $30.3 \pm 1.8$ \\
\hline $18: 0$ & $0 \cdot 1 \pm 0 \cdot 0$ & $\operatorname{tr}$ & $0.8 \pm 0.0$ & tr \\
\hline $18: 1$ & $30 \cdot 8 \pm 1 \cdot 2$ & $25 \cdot 1 \pm 1 \cdot 5$ & $19 \cdot 6 \pm 1 \cdot 0$ & $32 \cdot 5 \pm 1 \cdot 3$ \\
\hline $18: 2$ & $22 \cdot 6 \pm 0.7$ & $18.7 \pm 0.9$ & $7 \cdot 0 \pm 0.3$ & $\operatorname{tr}$ \\
\hline $18: 3$ & $4 \cdot 0 \pm 0.2$ & $8.5 \pm 0.2$ & $4 \cdot 3 \pm 0 \cdot 1$ & $\operatorname{tr}$ \\
\hline \multicolumn{5}{|c|}{ Phosphatidylglycerols: } \\
\hline $16: 0$ & $21.7 \pm 1.7$ & $33 \cdot 4 \pm 1 \cdot 5$ & $22 \cdot 8 \pm 1 \cdot 3$ & $11 \cdot 4 \pm 0 \cdot 2$ \\
\hline $16: 1$ & $\operatorname{tr}$ & $\operatorname{tr}$ & $9 \cdot 8 \pm 0.6$ & $20 \cdot 0 \pm 1 \cdot 2$ \\
\hline $16: 2$ & $24 \cdot 0 \pm 1 \cdot 1$ & $29 \cdot 7 \pm 1 \cdot 3$ & $17.8 \pm 1.0$ & $5 \cdot 6 \pm 0 \cdot 3$ \\
\hline $18: 0$ & $\operatorname{tr}$ & $\operatorname{tr}$ & $7 \cdot 3 \pm 0.5$ & $\operatorname{tr}$ \\
\hline $18: 1$ & $24 \cdot 3 \pm 0 \cdot 7$ & $19.9 \pm 0.8$ & $29 \cdot 4 \pm 1.6$ & $50 \cdot 0 \pm 1 \cdot 8$ \\
\hline $18: 2$ & $20.8 \pm 0.5$ & $10.6 \pm 0.6$ & $12.9 \pm 0.7$ & $\operatorname{tr}$ \\
\hline $18: 3$ & $9.2 \pm 0.4$ & $6.4 \pm 0.4$ & $\overline{t r}$ & $13 \cdot 6 \pm 0 \cdot 6$ \\
\hline \multicolumn{5}{|c|}{ Unidentified glycolipid: } \\
\hline $16: 0$ & $1.4 \pm 0.1$ & $25.9 \pm 1.0$ & $11 \cdot 0 \pm 0.5$ & $0.5 \pm 0.0$ \\
\hline $16: 1$ & $\operatorname{tr}$ & tr & $32.1 \pm 1.6$ & $30 \cdot 4 \pm 1 \cdot 1$ \\
\hline $16: 2$ & $35 \cdot 7 \pm 2 \cdot 0$ & $24.8 \pm 1 \cdot 2$ & $32 \cdot 1 \pm 1 \cdot 3$ & $38 \cdot 0 \pm 1 \cdot 2$ \\
\hline $18: 0$ & $10.0 \pm 0.5$ & $\operatorname{tr}$ & $1.9 \pm 0 \cdot 1$ & $0.2 \pm 0.0$ \\
\hline $18: 1$ & $23.9 \pm 0.9$ & $25 \cdot 7 \pm 0 \cdot 8$ & $15 \cdot 2 \pm 0 \cdot 8$ & $30: 4 \pm 1 \cdot 3$ \\
\hline $18: 2$ & $12.9 \pm 0.4$ & $15 \cdot 7 \pm 0.4$ & $7.8 \pm 0.4$ & $0.6 \pm 0.0$ \\
\hline $18: 3$ & $5.7 \pm 0.2$ & $7.8 \pm 0.3$ & $\operatorname{tr}$ & $\operatorname{tr}$ \\
\hline
\end{tabular}

cyanobacteria. All four freshwater cyanobacteria examined contain lipid classes known to predominate in photosynthetic prokaryotes and eukaryotes, specifically monogalactosyldiacylglycerols, digalactosyldiacylglycerols, sulphoquinovosyldiacylglycerols and phosphatidylglycerols (Quinn \& Williams, 1983). However, several basic differences are apparent between these cyanobacteria and photosynthetic eukaryotes. The nitrogen-fixing cyanobacteria Anabaena cylindrica, $N$. canina and $N$. muscorum contain alcohol glycosides; this observation is consistent with earlier results on other organisms (Nichols \& Wood, 1968b; Walsby \& Nichols, 1969; Winkenbach et al., 1972). However, we have also found this lipid class in marine cyanobacteria which were apparently incapable of nitrogen fixation (Al-Hasan et al., 1989). Alcohol glycosides have never been recorded in lipids of photosynthetic eukaryotes (for reviews see Kates, 1970; Quinn \& Williams, 1983). The three nitrogen-fixing freshwater cyanobacteria contain, in addition, a highly-polar unknown glycolipid not previously recorded. This compound was not found in the non-nitrogen-fixing Anacystis nidulans, or in any of the marine cyanobacteria we studied earlier (Al-Hasan et al., 1989), and has not been recorded in photosynthetic eukaryotes.

In $N$. muscorum (but not the other three cyanobacteria), the concentrations of the major lipid classes decrease in the dark (Fig. 3), although growth of all cyanobacteria slowed and photosynthetic activity and nitrogen fixation decreased $30-40 \%$. This response of $N$. muscorum is similar to that of many photosynthetic eukaryotes (Radwan et al., 1979).

Anabaena cylindrica contains a considerable concentration of linolenic acid $(18: 3)$ in its total lipid, showing similarity to photosynthetic eukaryotes (Kates, 1972; Quinn \& Williams, 1983). However, in contrast to eukaryotes, this cyanobacterium does not show any decrease in linolenic acid in its total lipid after incubation in the dark, nor is this fatty acid mainly concentrated in monogalactosyldiacylglycerols. This result contrasts with that of Zepke et al. (1978), who reported that in Nostoc calcicola, the major lipid classes, including monogalactosyldiacylglycerols, contain linolenic acid as a major constituent fatty acid. Palmitoleic acid $(16: 1)$, which is known to be confined to phosphatidylglycerols in photosynthetic eukaryotes (Hitchcock \& Nichols, 1971), is distributed among various major lipid classes of N. canina. N. canina and Anacystis nidulans also contain sterols, a lipid class also present in a few other cyanobacteria (De Souza \& Nes, 1968; Kohlhase \& Pohl, 1986; Sallal et al., 1987).

In conclusion, as with marine cyanobacteria (AlHasan et al., 1989), light-associated variations in the lipid and fatty acid composition of freshwater cyanobacteria are distinctly different from those reported for photosynthetic eukaryotes.

This work was supported by Kuwait University Research Council, grant nos SO 037 and SO 039.

\section{References}

Al-Hasan, R. H., Ali, A. M. \& Radwan, S. S. (1989). Effects of light and dark incubation on the lipid and fatty acid composition of marine cyanobacteria. Journal of General Microbiology 135, 865-872. 
Chalvardian, A. (1964). Fatty acids of brown and yellow fat in rats. Biochemical Journal 90, $518-521$.

De SouzA, N. J. \& NES, W. R. (1968). Sterols: isolation from a bluegreen alga. Science 162, 363.

DitTMER, J. C. \& Lester, R. L. (1964). A simple specific spray for the detection of phospholipids on thin layer chromatograms. Journal of Lipid Research 5, 126-127.

FolCh, J., LeE, M. \& Sloane Stanley, G. H. (1957). A simple method for the isolation and purification of total lipids from animal tissue. Journal of Biological Chemistry 226, 497-509.

GAVER, R. C. \& SwEELEY, C. C. (1965). Methods for methanolysis of sphingolipids and direct determination of long chain bases by gas chromatography. Journal of the American Oil Chemists Society $\mathbf{4 2}$ 294.

Haystead, A., Robinson, R. \& Steward, W. D. P. (1970). Nitrogenase activity in extracts of heterocystous and nonheterocystous blue-green algae. Archiv für Mikrobiologie 150, 235-243.

HiтchсосK, C. \& NichOLs, B. W. (1971). Plant Lipid Biochemistry. London \& New York: Academic Press.

Holton, R. W., BEACKER, H. H. \& ONORE, M. (1964). Effect of growth and temperature on the fatty acid composition of blue-green algae. Phytochemistry 3, 595-602.

KaTES, M. (1970). Plant phospholipids and glycolipids. Advances in Lipid Research 8, 225-265.

KATES, M. (1972). Techniques of Lipidology: Isolation, Analysis and Identification of Lipids, pp. 347-353. Amsterdam: North Holland Publishing Company.

Kohlhase, M. \& Pohl, P. (1986). Pilot scale and axenic mass cultivation of microalgae. II. Sterols of blue-green algae (cyanobacteria). Planta Medica 52, 416-417.

MANGold, H. K. \& Malins, D. C. (1960). Fractionation of fats, oils and waxes on thin layers of silicic acid. Journal of the American Oil Chemists Society 37, 383-385.

MENZieS, I. S. \& SEAKINS, J. T. (1976). Sugars. In Chromatographic and Electrophoretic Techniques, vol. 1, p. 183. Edited by I. Smith \& J. T. Seakins, London: William Heinemann.

Miwa, T. K., Mikolajezak, K. L., Earle, F. R. \& Wolff, I. A. (1960). Gas chromatographic characterization of fatty acids Identification constants for mono- and dicarboxylic methyl esters. Analytical Chemistry 32, 1739-1742.

NichoLs, B. W. (1964). Separation of plant phospholipids and glycolipids. In New Biochemical Separations, pp. 221-237. Edited by A. T. James \& L. J. Morries, London: Van Nostrand.

Nichols, B. W. \& WoOD, B. J. B. (1968a) The occurrence and biosynthesis of gamma linolenic acid in a blue-green alga, Spirulina platensis. Lipids 3, 46-50.

Nichols, B. W. \& WOOD, B. J. B. (1968b) New glycolipid specific to nitrogen-fixing blue-green algae. Nature, London 217, 767-768.

Parker, P. L., Van BaAlen, C. \& Maurer, L. (1967). Fatty acids in eleven species of blue-green algae: geochemical significance. Science 155, 707-708.

QuinN, P. J. \& Williams, W. P. (1983). The structural role of lipids in photosynthetic membranes. Biochimica et Biophysica Acta 737, 223266.

RaDWAN, S. S. (1978). Coupling of two-dimensional thin layer chromatography with gas chromatography for the quantitative analysis of lipid classes and their constituent fatty acids. Journal of Chromatographic Science 16, 538-542.

RADWAN, S. S. (1984). Glycerophospholipids. In Handbook of Chromatography: Lipids, vol. I, pp. 481-508. Edited by G. Zweig, J. Sherma \& H. K. Mangold. Boca Raton, Florida: CRC Press.

RadWan, S. S. \& Mangold, H. K. (1976). The lipids of plant tissue cultures. Advances in Lipid Research 14, 171-210.

RADWAN, S. S. \& MANGOLD, H. K. (1980). Biochemistry of lipids in plant cell cultures. In Advances in Biochemical Engineering pp. 109133. Edited by A. Fiechler, T. K. Ghose \& N. Blakebrough. Berlin: Springer.

RadWan, S. S., Mangold, H. K., Barz, W. \& HusemanN, W. (1979) Lipids in plant tissue cultures. VII. Reversible changes in the composition of lipids and their constituent fatty acids in response to alternate shifts in the mode of carbon supply. Chemistry and Physics of Lipids 35, 101-109.

SALLAL, A. K. \& NimER, N. A. (1988a). The intracellular localization of malate dehydrogenase in Anacystis nidulans. FEMS Microbiology Letters 50, 151-155.

Sallal, A. K. \& Nimer, N. A. (1988b). Shikonin isovalerate: an inhibitor of photosystem II in Chlorogloeopsis fritschii. Archives of Microbiology 150, 519-522.

Sallal, A. K., Ghannoum, M. A., Al-Hasan, R. H., Nimer, N. A. \& RADWAN, S. S. (1987). Lanosterol and diacylglycerophosphocholines in lipids from whole cells and thylakoids of the cyanobacteria Chlorogloeopsis fritschii. Archives of Microbiology 148, 1-7.

Sato, N. \& Murata, N. (1980). Temperature shift-induced responses in lipids in the blue-green alga Anabaena variabilis. The central role of diacylmonogalactosylglycerol in thermoadaptation. Biochimica et Biophysica Acta 619, 353-366.

Sato, N. \& Murata, N. (1982). Lipid biosynthesis in the blue green alga Anabaena variabilis. II. Fatty acids and lipid molecular species. Biochimica et Biophysica Acta 710, 270-289.

SiAKotos, N. A. \& Rouser, G. (1965). Analytical separation of nonlipid water soluble substances and gangliosides from other lipids by dextran gel column chromatography. Journal of the American Oil Chemists Society 42, 913-919.

Staht, E. (1967). Dunnschicht-chromatographie. Berlin: Springer.

Stainer, R. Y., Kunisawa, R., Mandel, M. \& Cohen-Bazire, G. (1971). Purification and properties of unicellular blue-green algae (order Chrococcales). Bacteriological Reviews 35, 171-205.

VIOQUE, E. (1984). Spray reagents for thin layer chromatography (TLC) and paper chromatography (PC). In Handbook of Chromatography: Lipids, vol. II, pp. 309-317. Edited by G. Zweig, J. Sherma \& H. K. Mangold. Boca Raton, Florida: CRC Press.

WalsBY, A. E. \& NichOLS, B. W. (1969). Lipid composition of heterocysts. Nature, London 221, 673-674.

WinkenbaCh, F., WolK, C. P. \& Jost, M. (1972). Lipids of membranes and of cell envelope in heterocysts of a blue-green alga. Planta 107, 69-80.

Zepre, H. D., Heinz, E., Radunz, A., Linscheid, M. \& Pesch, R. (1978). Combination and positional distribution of fatty acids in lipids from blue-green algae. Archives of Microbiology 119, 157-162. 